\title{
On the accuracy of integrated water vapor observations and the potential for mitigating electromagnetic path delay error in InSAR
}

\author{
D. Cimini ${ }^{1,2}$, N. Pierdicca ${ }^{3}$, E. Pichelli ${ }^{2}$, R. Ferretti ${ }^{2}$, V. Mattioli ${ }^{4}$, S. Bonafoni ${ }^{4}$, M. Montopoli ${ }^{2}{ }^{*}$, and D. Perissin ${ }^{5}$ \\ ${ }^{1}$ IMAA-CNR, Potenza, Italy \\ ${ }^{2}$ CETEMPS, University of L'Aquila, Italy \\ ${ }^{3}$ DIET, University of Rome "La Sapienza", Italy \\ ${ }^{4}$ DIEI, University of Perugia, Italy \\ ${ }^{5}$ ISEIS, Chinese University of Hong Kong, NT, Shatin, Hong Kong \\ *now at: University of Cambrige, UK
}

Correspondence to: D. Cimini (cimini@imaa.cnr.it)

Received: 18 November 2011 - Published in Atmos. Meas. Tech. Discuss.: 24 January 2012

Revised: 31 March 2012 - Accepted: 25 April 2012 - Published: 10 May 2012

\begin{abstract}
A field campaign was carried out in the framework of the Mitigation of Electromagnetic Transmission errors induced by Atmospheric Water Vapour Effects (METAWAVE) project sponsored by the European Space Agency (ESA) to investigate the accuracy of currently available sources of atmospheric columnar integrated water vapor measurements. The METAWAVE campaign took place in Rome, Italy, for the 2-week period from 19 September to 4 October 2008. The collected dataset includes observations from groundbased microwave radiometers and Global Positioning System (GPS) receivers, from meteorological numerical model analysis and predictions, from balloon-borne in-situ radiosoundings, as well as from spaceborne infrared radiometers. These different sources of integrated water vapor (IWV) observations have been analyzed and compared to quantify the accuracy and investigate the potential for mitigating IWVrelated electromagnetic path delay errors in Interferometric Synthetic Aperture Radar (InSAR) imaging. The results, which include a triple collocation analysis accounting for errors inherently present in every IWV measurements, are valid not only to InSAR but also to any other application involving water vapor sensing. The present analysis concludes that the requirements for mitigating the effects of turbulent water vapor component into InSAR are significantly higher than the accuracy of the instruments analyzed here. Nonetheless, information on the IWV vertical stratification from satellite observations, numerical models, and GPS receivers may provide valuable aid to suppress the long spatial
\end{abstract}

wavelength $(>20 \mathrm{~km})$ component of the atmospheric delay, and thus significantly improve the performances of InSAR phase unwrapping techniques.

\section{Introduction}

Spaceborne Interferometric Synthetic Aperture Radar (InSAR) imaging is a powerful tool for monitoring tectonic movements and landslides, and many other surface deformations, as well as to improve digital elevation models on the $\mathrm{cm}$ scale (Zebker and Goldstein, 1986; Gens and Van Genderen, 1996; Massonnet and Feigl, 1998; Hanssen, 2001). However, the atmosphere introduces propagation impairments in the two-way radar signal path; among these impairments, the principal limiting factor for InSAR applications is the propagation path delay, i.e. the excess path with respect to vacuum (Zebker et al., 1997; Hanssen et al., 1999). One of the largest sources of uncertainty in estimating the path delay originates from the large spatial and temporal variability of atmospheric water vapor (WV) and the corresponding fluctuations on the refractive index. This variability can be misinterpreted as a surface deformation and thus currently limits the quality of InSAR products. The effect of WV variability can be reduced by averaging a large number of interferograms (Zebker et al., 1997), and/or by analyzing a long series of interferometric phase of very stable and coherent

Published by Copernicus Publications on behalf of the European Geosciences Union. 
Permanent Scatterers (PS) (Ferretti et al., 2001; Perissin and Rocca, 2006; Perissin and Ferretti, 2007).

However, in case of sudden deformations of the Earth's surface (such as seismic events and landslides), the detection of which is one of the principal objectives of InSAR measurements, these averaging and multi-pass approaches cannot be used to efficiently remove the effect of WV variations, which in final cause a significant impact on the interferometric application. Thus, high-resolution information on the atmospheric WV content and its variation with time may be crucial to mitigate the effect of wet tropospheric path delay variations on the InSAR interferograms (Hanssen, 2001; Onn and Zebker, 2006). Indeed, several authors have investigated atmospheric delay estimation methods using meteorological modeling (Bonforte et al., 2001), multispectral imagery (Li et al., 2006), GPS signals (Onn and Zebker, 2006), or a combination of modelling and observations (Puysségur et al., 2007).

The WV observed from spaceborne or ground based instruments, as well as computed by Numerical Weather Prediction (NWP) models, have been subject of many studies, both experimental and theoretical (Bevis et al., 1992; Revercomb et al., 2003; Gao and Kaufman, 2003). Water vapor is one of the most significant constituents of the atmosphere because its changes of phase are responsible for cloud and precipitation and because its interaction with radiation is a crucial factor in the energy budget of the Earth. Despite of its importance in atmospheric processes over a wide range of spatial and temporal scales, water vapor is one of the least understood and poorly described components of the atmosphere.

In addition, water vapor fluctuations are a major error source in ranging measurements through the Earth's atmosphere and represent therefore the major limitation in all space geodesy applications for high precision positioning, especially when in near real-time. Beside InSAR, these applications include satellite altimetry (Desportes et al., 2007), very long baseline interferometry (Treuhaft and Lanyi, 1987), and GPS (Sohleim et al., 1999). Therefore it is important to understand at what extent the water vapor can be reliably measured and predicted. On this respect, InSAR applications represent a valuable and challenging testbed, since it requires very high spatial resolution (of the same order of the radar image resolution) and timeliness (lag of the satellite overpass).

Therefore, the European Space Agency (ESA) sponsored a project called METAWAVE (Mitigation of Electromagnetic Transmission errors induced by Atmospheric Water Vapor Effects) aimed at investigating the potential of mitigating WV effects into InSAR imagery by means of external information on WV distribution from ancillary ground- and satellite-based observations and/or from the output of atmospheric numerical models. In the framework of METAWAVE, a field campaign was conducted for collecting an extensive data set of water vapor observations, for validating the different sources against reference data, and finally for investigating the accuracy of currently available estimates of atmospheric columnar integrated WV. Therefore, the rationale behind the METAWAVE campaign can be summarised as the following: there is need for validating and quantifying the accuracy of various WV estimates before their potential can be evaluated with respect to InSAR requirements and before attempting any WV mitigation. The field campaign performed in the framework of METAWAVE provided us with a valuable and particularly diversified data set, useful to gain insights on the water vapor measurements in general, not limited to the InSAR tropospheric correction only.

InSAR propagation path delay is affected by the signal roundtrip through the atmosphere, and thus by the atmospheric gases distributed along the signal path (Hanssen et al., 1999). It is demonstrated (Davis et al., 1985; Bevis et al., 1994) that the wet component of the delay, due to the WV alone and therefore subjected to its three dimensional (3-D) variability, is very much correlated to a path-integrated quantity, that is the columnar integrated water vapor (IWV) (Mattioli et al., 2005). The other component of the path delay, which is the dry term due to the other atmospheric gases, depends on dry pressure and temperature profiles. In many applications, including GPS, an hydrostatic component is usually estimated from surface pressure (Saastamoinen, 1972), for instance by exploiting data from meteorological ground stations. The error introduced by the assumption of hydrostatic equilibrium is typically of the order of $0.01 \%$, which correspond to $0.2 \mathrm{~mm}$ in the delay at zenith (Elgered, 1993). However, it has been shown (Doin et al., 2009) that the spatial variation of temperature stratification induces variations of delay with elevation and thus non negligible phase delay patterns in InSAR. Although the delay due to WV is much smaller (generally less than $35 \mathrm{~cm}$ ) than the other component of the delay $(\sim 2.3 \mathrm{~m})$ and the variations of the dry or hydrostatic components represent an important issue to be faced for correcting InSAR, the wet delay is far more difficult to predict due to its high spatial and temporal variability. Therefore, hereafter we will focus our attention on the wet delay and in particular on IWV. For the purpose of using IWV fields for mitigating tropospheric effects into SAR interferograms, it is also significant to analyze the trend of IWV with respect to altitude. In fact, IWV generally decreases with increasing terrain altitude because of the tapering of the atmosphere over higher surfaces, but the actual IWV vs. height trend is associated to the atmospheric vertical stratification, which in turns depends on the specific meteorological conditions. Such a stratification affects the propagation delay and thus the SAR interferogram phase as function of the surface height and it introduces an error in the associated estimates of the relative displacement between points at different altitude. For instance, it has been demonstrated that over a volcano the stratified part of the atmospheric delay, inducing a signal correlated with the elevation, mimics the signal due to deflation related to magma reservoir replenishment or withdrawal (Doin et al., 2009). 
In this paper we exploit the dataset collected during the METAWAVE campaign, including (i) products from NWP modelling, (ii) observations from radiosounding, ground based microwave radiometers, and GPS receiver network, and finally (iii) observations from spaceborne infrared radiometers. In this analysis we perform an intercomparison of the different sources, including a triple collocation analysis, aiming to single out data quality and reliability in view of the effect mitigation into InSAR and other applications requiring accurate information on tropospheric water vapour.

The paper is organized as the following: Sect. 2 describes the available data set, Sect. 3 summarizes the statistical methodology used for data intercomparison, Sect. 4 reports the results of the data analysis, and finally Sect. 5 summarises the results and draws the final conclusions.

\section{Data set}

The Water Vapour Intensive Observational Period (WVIOP) has been conducted in the area of Rome during the 2 weeks from 19 September to 4 October 2008. In this period there were two ENVISAT passages over Rome, on 20 September and 3 October, providing two InSAR images from the Advanced Synthetic Aperture Radar (ASAR).

The sources of WV estimates that have been considered in this comparison effort include the following:

- Observations: WV measurements taken both directly in situ and remotely sensed from satellite- and ground-based sensors.

- Simulations: WV distribution computed by a high resolution numerical weather prediction model

- Analysis: WV distribution computed by a global numerical weather analysis model assimilating all the data available from operational weather observing systems.

Since the InSAR propagation path delay is affected by the atmospheric WV distributed along the signal path, in this paper we focus on a path-integrated quantity, the IWV. It is worth underlining that in the remaining of the paper, centimetres $(\mathrm{cm})$ of WV will always mean IWV, if not else specified. This is important to avoid confusion with the wet delay component.

The experimental set-up designed for the METAWAVE WVIOP in Rome is pictured in Fig. 1 and it included, among others, the following instrumentations:

- Dual channel microwave radiometer (MWR) at 23.8 and $31.4 \mathrm{GHz}$ located at the Department of Electronic Engineering building of Sapienza University of Rome (DIESAP)

- Network of eleven GPS receivers distributed within Rome and in its surroundings.

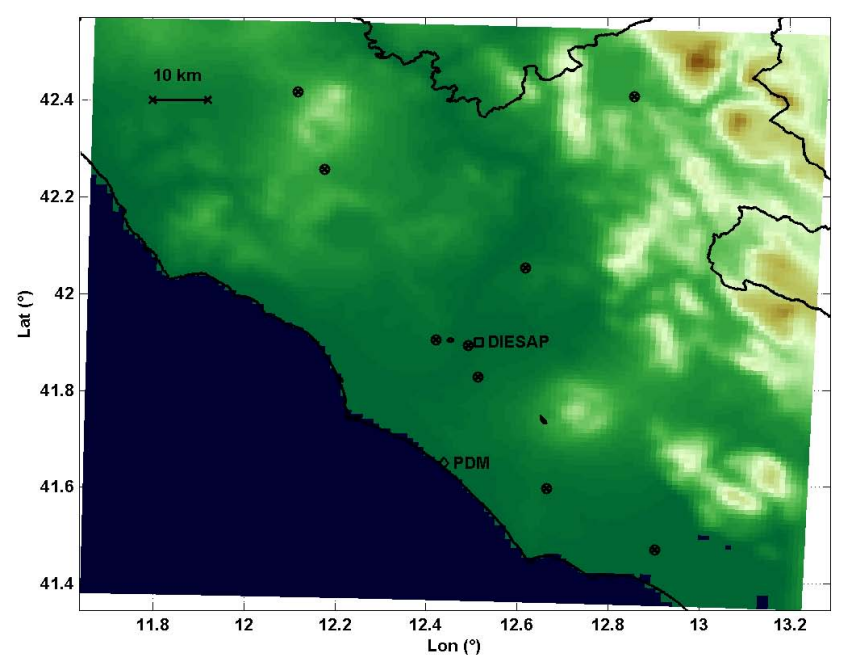

Fig. 1. The area interested by the METAWAVE WVIOP. The elevation of the high-resolution inner MM5 domain is mapped in colors (from 0 to $1871 \mathrm{~m}$ above sea level). Crossed circles indicate the location of GPS receivers. MWR and PRS were located at DIESAP (square), while ORS were launched at PDM (diamond).

- Portable radiosonde station (PRS) at DIESAP operated by Colorado State University (CSU) Microwave System Laboratory

- Operational radiosonde station (ORS) at Pratica di Mare (PDM) operated by the Italian General Office for the Aereospace and Meteorology (USAM), National Center for Aeronautic Meteorology and Climatology (CNMCA).

The METAWAVE WVIOP included also the deployment of a network of three 4-channel compact microwave radiometers, whose outcome is treated in a separate paper (Sahoo et al., 2011). For the analysis provided in this paper, we use data from the MWR, GPS receivers, and PRS and ORS radiosonde profiles. In addition, IWV maps estimated by satellite passive observations were collected from the following sensors:

- Medium Resolution Imaging Spectrometer (MERIS) on board of the ESA ENVISAT satellite

- Moderate-resolution Infrared Spectrometer (MODIS) on board of the NASA Terra satellite

- MODIS on board of the NASA Aqua satellite

Here we use the IWV operational products provided by the MODIS and MERIS science teams. In particular:

- MODIS: IWV maps are estimated from MODIS observations using two algorithms, one relying on observations at thermal infrared (TIR, 6-10 $\mu \mathrm{m}$ ) (King et al., 2003) and the other relying on near infrared (NIR, 
$0.85-1.2 \mu \mathrm{m}$ ) channels (Gao and Kaufman, 2003). The MODIS operational IWV product is provided at $5 \mathrm{~km}$ horizontal resolution for the TIR-based algorithm, while at $1 \mathrm{~km}$ for the NIR-based algorithm. In the following, we use data from both the MODIS units onboard the Terra and Aqua NASA satellites, with an emphasis on MODIS on Terra since it overpasses within one hour with respect to MERIS on ENVISAT.

- MERIS: IWV maps are estimated from MERIS obser-

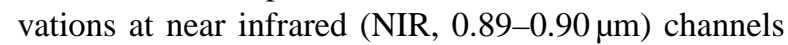
(Fischer and Bennartz, 1997). The horizontal resolution is $0.3 \mathrm{~km}$.

IWV maps estimated with all the above methods are considered in the following analysis. Finally, WV density profiles and associated IWV values were extracted from three-dimensional WV distribution simulated by numerical models, as:

- ECMWF: European Center for Medium range Weather Forecasting (ECMWF) global analysis at $0.25^{\circ}$ resolution (corresponding to $\sim 25 \mathrm{~km}$ at middle latitude).

- MM5: 5th generation PSU/NCAR Mesoscale Model (MM5) (Dudhia, 1993; Ferretti et al., 2003) with four two-way nested domains. The resolution of the inner domain used here, corresponding to the HR area in Fig. 1, is $1 \mathrm{~km}$. MM5 forecast was initialized with ECMWF analysis at least $8 \mathrm{~h}$ ahead.

Note that the non hydrostatic mesoscale model MM5, associated with physical parameterizations specific for the local scale, is able to forecast 3-D atmospheric fields at higher resolution than the one resolved by a synoptic scale model. This allows the prediction of future meteorological scenarios taking into account high variability details that are not detectable in the ECMWF synoptic analysis product. Table 1 summarises the data set collected during the WVIOP in Rome.

\section{Methodology}

A validation effort needs a reference with known and documented accuracy to compare against. In the following analysis, we consider three types of IWV products: WV profiles, punctual column integrated WV (IWV), and two dimensional (2-D) IWV horizontal maps. For WV profiles, we consider radiosonde observations (RAOB) as the reference sources. Although depending upon sensor type, radiosondes suffer from some error sources that degrade humidity measurements; these errors include daytime dry bias induced by solar radiation and time lag and calibration drift at low temperatures. Nevertheless, up to now radiosoundings provide the most accurate information on the vertical structure of the troposphere and lower stratosphere. For the type used during the experiment, documented accuracy is of about $5 \%$ (Mattioli et al., 2007; Vömel et al., 2007).

For ground-based IWV point source, reference is considered the dual channel MWR, with accuracy of the order of $0.1 \mathrm{~cm}$ in IWV (i.e. $1 \mathrm{~kg} \mathrm{~m}^{-2}$ ) (Cimini et al., 2003). The horizontal resolution of a single radiometer is determined by the antenna beamwidth. Assuming a beamwidth of $4-5^{\circ}$, which applies for most of commercial MWR including the one used in this study, the field of view is about $0.5 \mathrm{~km}$ at $6 \mathrm{~km}$ altitude.

For IWV maps, the reference is considered to be the GPS. Although IWV data from GPS can be turned into dense 2-D maps using statistical interpolation (Basili et al., 2004), due to the low resolution of the GPS receiver network within the HR area, GPS IWV estimates are considered as maps of scattered point measurements at the receivers' locations. GPS data were processed with the Bernese software package. The dry-Niell in conjunction with the wet-Niell mapping function were applied. Note that IWV from GPS is modeled as an average of all GPS satellite observations above the chosen cutoff angle and its accuracy depends on errors associated with the estimation of the total tropospheric signal delay (Bevis et al., 1992), the estimation of the zenith hydrostatic delay (Saastamoinen, 1972), and in the estimation of the wet delay transfer function (Bevis et al., 1994). These errors are independent and correspond to an equivalent IWV retrieval error of $0.07-0.15 \mathrm{~cm}, 0.02 \mathrm{~cm}$, and $0.01 \mathrm{~cm}$, respectively (Niell et al., 2001; Gutman et al., 2004), for a total estimated retrieval error of $0.1-0.15 \mathrm{~cm}$ (Mattioli et al., 2005).

For 2-D IWV distribution at high resolution, it is anticipated that MERIS IWV retrievals will be used as reference. The MERIS retrieval algorithm relates the IWV to the reflectance ratio of two channels located at $890 \mathrm{~nm}$ and $900 \mathrm{~nm}$ (Fischer and Bennartz, 1997), and it is based on the assumption that a logarithmical relation between the absorber mass and extinction exists, with also an empirical quadratic correction term. Accuracy for this retrieval approach is given with a typical error around $10 \%$. MERIS IWV maps over land have been compared against GPS and found in agreement within $1.5 \mathrm{~mm}$ (Li et al., 2006).

Once that the reference sources have been identified, we process the data in order to co-locate the independent observations and compute statistical indices, such as the average (AVG), standard deviation (STD), and root-mean-square (RMS) differences, the correlation coefficient (COR), and finally the slope (SLP) and intercept (INT) of a least-square linear fit.

It must be considered, however, that any reference source used for validation has its own error, which affects the statistical indices assigned to the source under test. To account for the errors inherently present in any of the considered IWV data, we performed a triple-collocation analysis, following the approach proposed by Stoeffelen (1998); Freilich and Vanhoff (1999) and Freilich and Vanhoff (unpublished data, 2001). These papers develop and demonstrate an approach 
Table 1. Sources of measurements of WV distribution collected during the METAWAVE WVIOP in Rome. The letters "h" and "v" stand for horizontal and vertical resolution, respectively.

\begin{tabular}{|c|c|c|c|c|}
\hline Sensor & Location/Coverage & Operated by & Products & Resolution \\
\hline MWR & DIESAP & UNIPG & IWV (point) & h: $4^{\circ}$ beamwidth; v: n.a. \\
\hline GPS & Within HR area & & IWV (map) & h: $\sim 10 \mathrm{~km} ;$ v: n.a. \\
\hline PRS & DIESAP & $\mathrm{CSU}$ & WV (profile) & h: n.a; v: $\sim 5 \mathrm{~m}$ \\
\hline ORS & PDM & $\mathrm{AM}$ & WV (profile) & h: n.a; v: $\sim 5 \mathrm{~m}$ \\
\hline MODIS & HR & NASA & WV (maps) & h: 1 (NIR)-5 (TIR) km; v: n.a \\
\hline MERIS & HR & ESA & WV (maps) & h: $0.3 \mathrm{~km} ; \mathrm{v}: \mathrm{n} . \mathrm{a}$ \\
\hline MM5 & HR & CETEMPS & WV (3-D) & $\begin{array}{l}\mathrm{h}: 1.0 \mathrm{~km} ; \mathrm{v} \text { : varies }(\sim 20-50 \mathrm{~m} \text { for } \mathrm{h}<500 \mathrm{~m} \\
\sim 250 \mathrm{~m} \text { for } \mathrm{h}<3 \mathrm{~km}, \sim 500 \mathrm{~m} \text { for } 3<\mathrm{h}<15 \mathrm{~km})\end{array}$ \\
\hline ECMWF & LR & ECMWF & WV (3-D) & $\begin{array}{l}\mathrm{h}: 28 \mathrm{~km} \text {; v: varies }(\sim 20-100 \mathrm{~m} \text { for } \mathrm{h}<500 \mathrm{~m} \text {, } \\
\sim 100-300 \mathrm{~m} \text { for } \mathrm{h}<3 \mathrm{~km}, \sim 500 \mathrm{~m} \text { for } 3<\mathrm{h}<15 \mathrm{~km})\end{array}$ \\
\hline
\end{tabular}

for validating multiple, collocated wind speed data sets. Stoeffelen (1998) and Freilich and Vanhoff (1999) have independently proposed methods for performing validation and error modelling without assumptions on the statistical properties of the true distribution and the error distribution, taking the advantage of the availability of three independent and collocated data sets. The gain comes in more accurate assessment of variance and less possible systematic contamination that can obscure real geophysical signals in the data from a given sensor. A similar approach has been used by Caires and Sterl (2003), and later applied to the validation of global soil moisture estimates (Scipal et al., 2008; Miralles et al., 2010; Dorigo et al., 2010).

Here we adopt the formalism described by Stoeffelen (1998), which was originally developed for ocean wind speed scatterometer observations; the formalism itself is quite general, such that it can be easily adapted to IWV observations. In the following the procedure is just briefly reviewed; further details can be found in Stoeffelen (1998). Suppose three measurement systems X, Y, and Z measuring a true variable $t$ (IWV in our case). Calling $x, y$, and $z$, respectively the output signals of the three measurement systems $\mathrm{X}, \mathrm{Y}$, and $\mathrm{Z}$, let us assume the following error model:

$x=t+\delta x$

$y=s_{y}(t+\delta y)$

$z=s_{z}(t+\delta z)$

where

- $\delta x, \delta y$, and $\delta z$ are the random observation errors with zero mean (i.e. no bias) and variance $\varepsilon_{x}^{2}=<\delta_{x}^{2}>$, $\varepsilon_{y}^{2}=<\delta_{y}^{2}>$, and $\varepsilon_{z}^{2}=<\delta_{z}^{2}>$, where $<\ldots>$ indicate the expected value;

- the true variable $t$ is supposed to have variance $\sigma^{2}$;

- $s_{y}$ and $s_{z}$ are the scaling constants.

The error model assumes negligible bias, since this is valid to good approximation for IWV and biases can be easily removed otherwise. Therefore, for simplicity we remove the mean and the systematic errors of the true distribution, so that $<t>=<\delta_{x}>=<\delta_{y}>=0$ and $\sigma^{2}=<t^{2}>$.

Usually the three systems do not represent the same spatial scale of the observed field (IWV in our case); thus it is assumed herewith that systems $\mathrm{X}$ and $\mathrm{Y}$ can resolve smaller scales than system $\mathrm{Z}$ by introducing $r^{2}$ as the variance common to these smaller scales, i.e. by definition the correlated part of the representativeness errors of $\mathrm{X}$ and $\mathrm{Y}$. In other words, variable $t$ refers to the large scale features of the observed field, which is measured by $\mathrm{Z}$, whereas the small scale features sensed by $\mathrm{X}$ and $\mathrm{Y}$ are embedded in the noise terms $\delta x$ and $\delta y$. Except for the representativeness error, it is assumed that the errors of the different observation systems are uncorrelated, that is $\left.\left\langle\delta_{x} \delta_{y}\right\rangle=r^{2} ;<\delta_{x} \delta_{z}\right\rangle=0$; and $<\delta_{z} \delta_{y}>=0$. Therefore, under the premise that we estimate $r^{2}$, the scaling constants can be derived from the different covariances:

$s_{y}=<y z><z x>^{-1}$

$s_{z}=<y z>\left(<x y>-r^{2} s_{y}\right)^{-1}$

while all random errors of the observation systems $\mathrm{X}, \mathrm{Y}$, and $\mathrm{Z}$ can be easily derived by resolving pairwise systems of three equations with three unknowns:

$\sigma^{2}=s_{z}^{-1}<x z>=s_{z}^{-1} s_{y}^{-1}<z y>=s_{y}^{-1}<x y>-r^{2}$

$\varepsilon_{x}^{2}=<x^{2}>-\sigma^{2}$

$\varepsilon_{y}^{2}=s_{y}^{-2}<y^{2}>-\sigma^{2}$

$\varepsilon_{z}^{2}=s_{z}^{-2}<z^{2}>-\sigma^{2}$

In our analysis the triple collocation approach is applied to IWV products acquired from satellite observations, NWP modeling, and ground-based GPS receivers stations. All three products contain errors arising from distinct sources. Satellite estimates are affected by instrument noise, semitransparent clouds, and uncertainty in surface emission modelling; model-based predictions suffer from a simplified parameterization, initialization data error, soil moisture uncertainties, and error propagation in the forecast; IWV from 

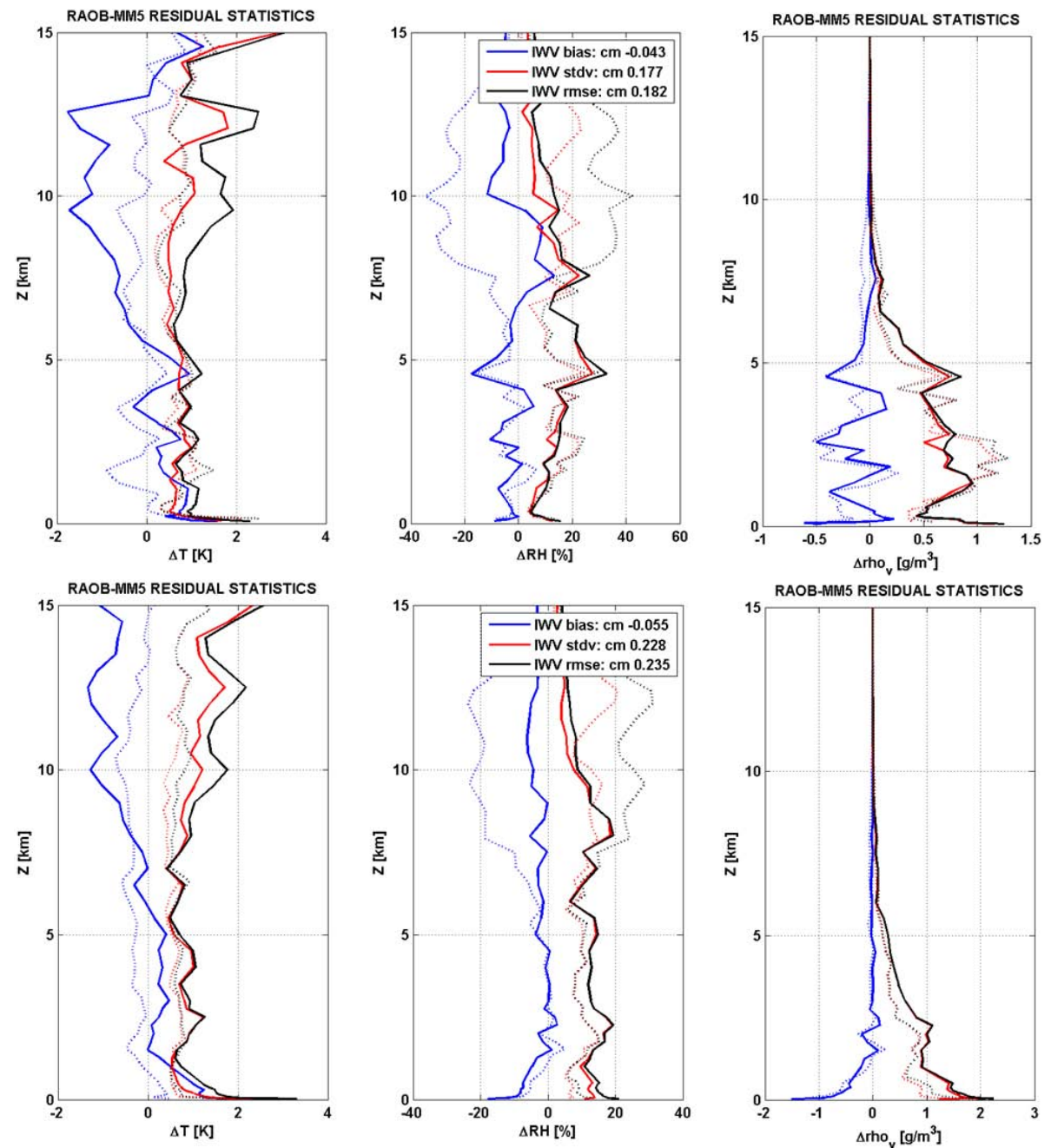

Fig. 2. Statistics of the difference $(\Delta)$ of MM5 (solid) and ECMWF (dotted) temperature (left), relative humidity (center), and water vapor density (right) with respect to RAOB lunched at DIESAP (top) and PDM (bottom). Blue lines indicate profiles of mean difference (bias), red lines indicate standard deviation, and black lines indicate root-mean-squared difference.

single GPS receivers are affected by measurement errors (e.g. multipath) and the representativeness error due to the inherent spatial heterogeneity of water vapor fields. In our implementation, we have adapted the formalism above for IWV and identified as systems X, Y, and Z, the ground-based GPS receiver network, MERIS, and MM5, respectively. In summary, the simple analytical model described above relates measured and/or modeled IWV to the true values, taking into account errors in the estimates as well as in the reference data, as it is demonstrated that omitting the latter errors would lead to erroneous statistical parameter estimates (Stoffelen, 1998; Freilich and Vanhoff, 1999; Freilich and Vanhoff, unpublished data, 2001; Quilfen et al., 2001).

\section{Results}

This section presents the statistical scores found by comparing the measurements provided by the different sources as such, and then obtained by means of the triple collocation approach. A summary review and critical comparison of the results is than provided.

\subsection{Water vapor profiles}

During the METAWAVE WVIOP campaign, radiosondes were launched from two sites in the HR area. Operational four-daily launches were performed by USAM from the base in Pratica di Mare (PDM); the PDM site falls within the HR square but outside the red triangle in Fig. 1. Eight dedicated launches from the portable radiosonde station PRS were performed at DIESAP, i.e. the northern most node of the triangle in Fig. 1. All the radiosondes launched from both sites were 
Vaisala RS92. The RAOB launched at DIESAP were used to validate the temperature and humidity profiles provided by the MM5 forecast and the ECMWF analysis output. Analogously, the same analysis was performed at PDM using the ORS RAOB launched by USAM.

Figure 2 shows the statistical comparison of MM5 prediction and ECMWF analysis profiles with respect to RAOB. Note that the MM5 run is initialized using ECMWF analysis, though the comparison is carried out more than eight hours after the start time. Considering the RAOB from DIESAP, only six out of eight launches were successful; thus six cases of nearly simultaneous match-ups of RAOB, MM5, and ECMWF are available. Relative humidity profiles from MM5 and ECMWF agree with RAOB with a bias smaller than $10 \%$ and a rms less than $20 \%$ in the lower $5 \mathrm{~km}$. In terms of WV density, the bias is smaller than $0.5 \mathrm{~g} \mathrm{~m}^{-3}$ and the rms is within $1.0 \mathrm{~g} \mathrm{~m}^{-3}$ for both MM5 and ECMWF with respect to RAOB.

The WV profiles used for Fig. 2 have also been integrated vertically to compute IWV. The MM5 output and ECMWF analysis closest to DIESAP and PDM have been used to compute the IWV burden at those two sites. For IWV, bias, std and rms result in $0.05,0.177,0.184 \mathrm{~cm}$, respectively. Similar results were obtained for the PDM site (46 match-up cases), though there appear larger differences near the surface (bias up to $20 \%$ in relative humidity and $-1.5 \mathrm{~g} \mathrm{~m}^{-3}$ in WV density). The fact that PDM site is very close to the sea could justify this larger discrepancy. The same analysis was repeated for the Weather Research and Forecast (WRF) model (Michalakes et al., 1998), of newer generation with respect to MM5, showing no significant improvement for relative humidity and WV density profiles, though these results will be further analyzed in future work.

The results above give confidence in the ability of MM5 to reproduce the water vapor vertical profile and IWV, suggesting for the use of the whole model output at high spatial and temporal resolution. This represents the added value compared to ECMWF analyses, which are only available for the past (i.e. no forecast) and with rather coarse temporal $(6 \mathrm{~h})$ and spatial $\left(0.25^{\circ}\right)$ resolution.

\subsection{Integrated water vapor}

Ground-based IWV estimates during the WVIOP in Rome were obtained from the dual channel MWR located at DIESAP and from the GPS receivers distributed over the HR area in Fig. 1. Moreover, as mentioned in the previous section, IWV values at different times and locations were computed from WV profiles measured by RAOB (from DIESAP and PDM), and computed by MM5 and ECMWF.

The IWV time series for the entire WVIOP from the sources available at DIESAP and PDM are plotted in Fig. 3. Note that there were just 6 RAOB at DIESAP while 46 at PDM; on the other hand MWR and GPS were available at DIESAP but not at PDM. The top panel shows that the time
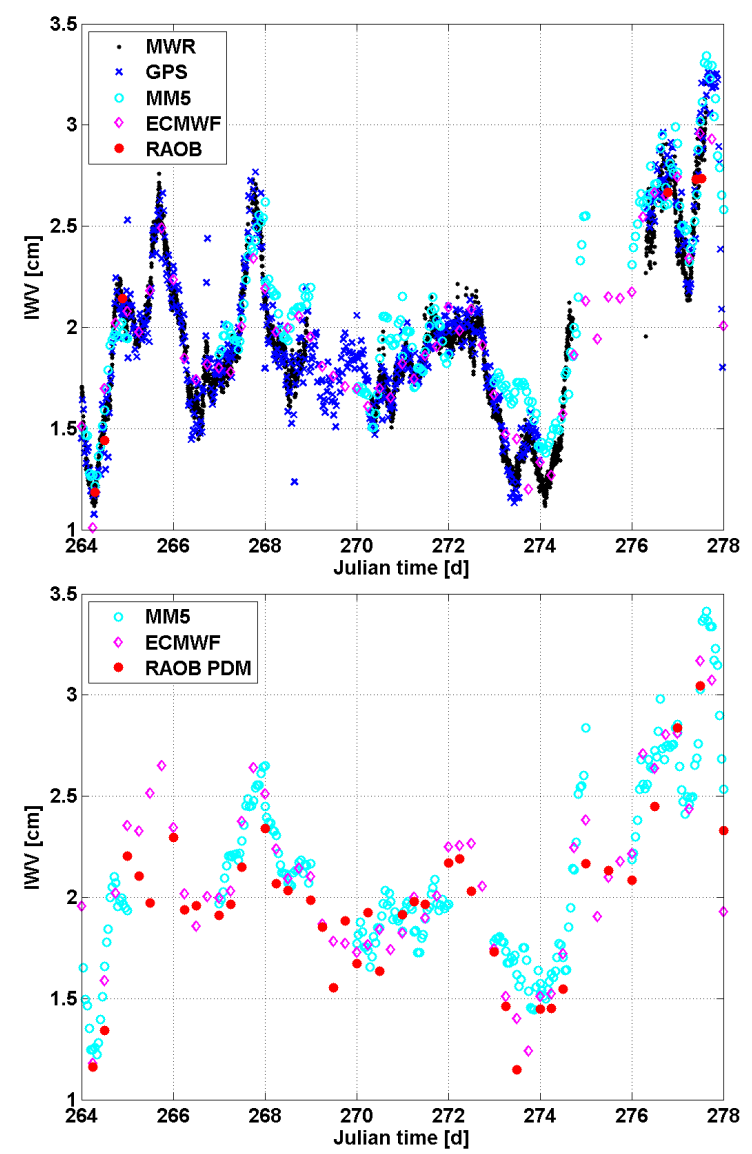

Fig. 3. Time series of IWV from MWR (black dots), GPS (blue $\mathrm{x})$, MM5 (cyan circles), ECMWF (magenta diamonds), and RAOB (red solid circles). Top: at DIESAP. Bottom: at PDM.

series of GPS and MWR are very much consistent and that MM5 predictions follow quite well the IWV values measured by both MWR and GPS. However, there are periods in which MM5 tends to significantly overestimate IWV with respect to MWR/GPS (up to $40 \%$ at times), as between julian day 268-269 (e.g. 24 September) and 273-274 (e.g. 29 September), 2008. Scatter plots of IWV from different sources are shown in Fig. 4, each one reported with its main statistics. Statistics for all the scatter plots are then summarised in Table 2 for convenience. Table 2 confirms that GPS and MWR are the sources exhibiting the best agreement, despite of the rather large test sample and range of conditions. Assuming the MWR and GPS errors to be independent and equally distributed, the rms difference of $0.1 \mathrm{~cm}$ would indicate an intrinsic error of the order of $0.07 \mathrm{~cm}$ for each instrument. However, we expect the overall accuracy of MWR to be better than that of GPS, since multipath and other sources of error in the GPS estimation of the total tropospheric signal delay already contribute themselves for an IWV error larger than $0.07 \mathrm{~cm}$. This will be further discussed in the next section. Similarly, Fig. 4 and Table 2 show that MWR is also matching very well the reference RAOB at the same site. 

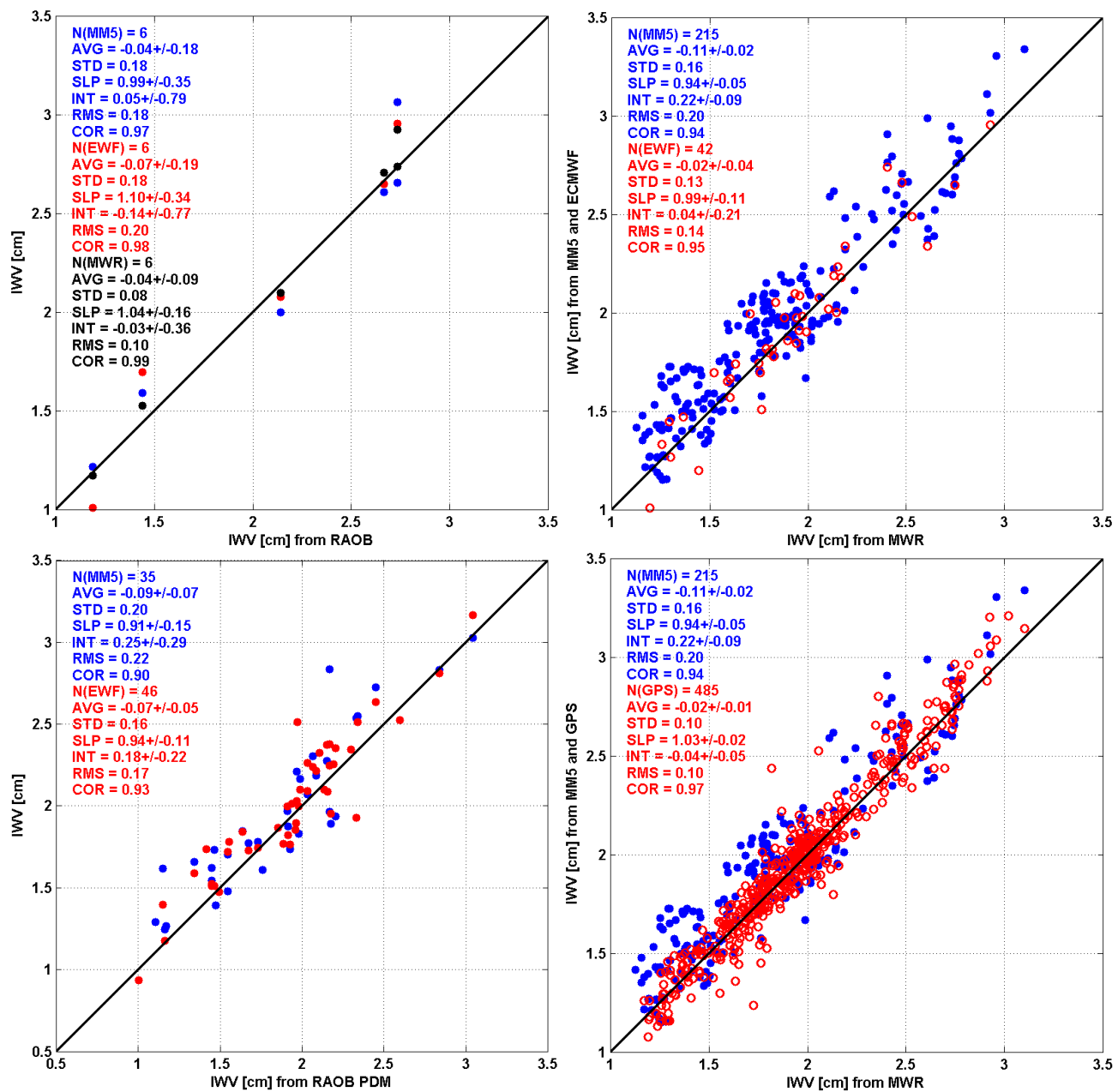

Fig. 4. Scatter plots of IWV from different sources. Left: the reference source is RAOB (top: at DIESAP; bottom: at PDM). Right: the reference source is MWR (top: MM5 and ECMWF; bottom: MM5 and GPS). The mean x-y difference (AVG), the standard deviation (STD) and root-mean-square (RMS) differences, the correlation coefficient (COR), and finally the slope (SLP) and intersect (INT) of a least-square linear fit are reported. Values for AVG, STD, RMS values are in $\mathrm{cm}$.

Table 2. Summary of IWV statistics extracted from the scatter plots in Figs. 4 and 6.

\begin{tabular}{lrrrrrrr}
\hline & $\begin{array}{r}\text { Sample } \\
\text { size }\end{array}$ & $\begin{array}{r}\text { AVG } \\
{[\mathrm{cm}]}\end{array}$ & $\begin{array}{r}\text { STD } \\
{[\mathrm{cm}]}\end{array}$ & $\begin{array}{r}\text { RMS } \\
{[\mathrm{cm}]}\end{array}$ & COR & SLP & $\begin{array}{r}\text { INT } \\
{[\mathrm{cm}]}\end{array}$ \\
\hline RAOB DIESAP vs. MWR & 6 & -0.04 & 0.08 & 0.10 & 0.99 & 1.04 & -0.03 \\
RAOB DIESAP vs. ECMWF & 6 & -0.07 & 0.18 & 0.20 & 0.98 & 1.10 & -0.14 \\
RAOB DIESAP vs. MM5 & 6 & -0.04 & 0.18 & 0.18 & 0.97 & 0.99 & 0.05 \\
RAOB PDM vs. ECMWF & 46 & -0.07 & 0.16 & 0.17 & 0.93 & 0.94 & 0.18 \\
RAOB PDM vs. MM5 & 35 & -0.09 & 0.20 & 0.22 & 0.90 & 0.91 & 0.25 \\
MWR vs. ECMWF & 42 & -0.02 & 0.13 & 0.14 & 0.95 & 0.99 & 0.04 \\
MWR vs. MM5 & 215 & -0.11 & 0.16 & 0.20 & 0.94 & 0.94 & 0.22 \\
MWR vs. GPS & 485 & -0.02 & 0.10 & 0.10 & 0.97 & 1.03 & -0.04 \\
GPS vs. MERIS & 41 & 0.01 & 0.10 & 0.10 & 0.97 & 0.94 & 0.08 \\
GPS vs. MODIS-IR & 31 & 0.00 & 0.19 & 0.19 & 0.84 & 0.81 & 0.28 \\
GPS vs. MODIS-NIR & 33 & -0.07 & 0.29 & 0.30 & 0.69 & 0.60 & 0.68 \\
GPS vs. MM5 & 210 & -0.02 & 0.20 & 0.20 & 0.93 & 0.84 & 0.30 \\
\hline
\end{tabular}



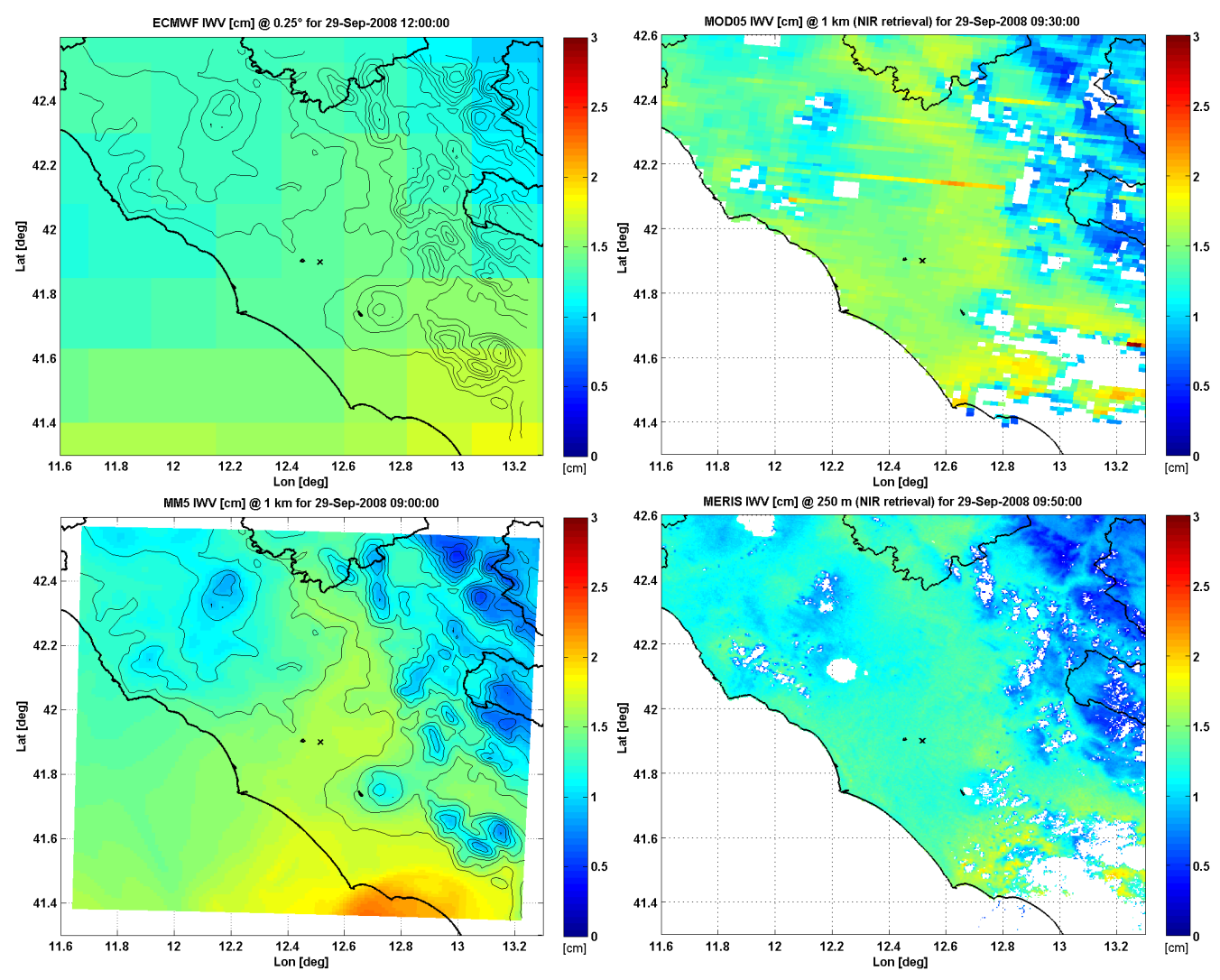

Fig. 5. IWV maps from different estimate sources. Left: ECMWF (top) and MM5 (bottom); black thin lines indicate surface contour at $200 \mathrm{~m}$ intervals from 100 to $1700 \mathrm{~m}$ Right: MODIS (top) and MERIS (bottom). Note that NIR-based IWV retrievals (left panels) are not available over ocean. Note also that MODIS and MERIS infrared observations are affected by clouds and thus are screened using the operational cloud mask provided in the original MODIS and MERIS metadata.

In addition, we see that MM5 differs from the ground measurements (RAOB, MWR, and GPS) by $\sim 0.2 \mathrm{~cm} \mathrm{rms,} \mathrm{a} \mathrm{fac-}$ tor of two with respect to the MWR-GPS or MWR-RAOB rms difference $(\sim 0.1 \mathrm{~cm})$, indicating that MM5 error is likely larger than $0.18 \mathrm{~cm}$. Note also that in Fig. 4 ECMWF shows good agreement with the MWR, with negligible bias, slope close to unity, and rms of $0.14 \mathrm{~cm}$, some $40 \%$ larger than the GPS-MWR rms difference. Our results are slightly better than those shown by Bock et al. (2006), indicating good accuracy for ECMWF data aside from mountainous regions. In this sense, the availability of collocated radiosonde, GPS, and MWR represents an independent validation for ECMWF IWV, which is of general interest as ECMWF moisture data is often and widely used as benchmark and validation for satellite retrieval algorithms.

IWV maps at low $(\sim 5 \mathrm{~km})$, medium $(\sim 1 \mathrm{~km})$, and high resolution $(\sim 0.3 \mathrm{~km})$ respectively from MODIS, MM5, and MERIS, have been compared and validated against IWV retrieved by MWR (single point) and GPS (11 point-like receivers). A qualitative comparison of IWV maps from the above sources for one case is shown in Fig. 5, where the different spatial resolutions can be appreciated. Note that cou- pling the information from ECMWF on vertical stratification at $\sim 25 \mathrm{~km}$ with information from a higher resolution Digital Elevation Model (DEM) (as for example the one used by MM5 at $1 \mathrm{~km}$ ), IWV can be estimated at the DEM resolution and it would show the patterns related to orography. By visually comparing the IWV maps from MM5 and ECMWF, one may appreciate the ability of MM5 to discriminate IWV spatial variability at much finer resolution, somewhat comparable with the one from MERIS. This qualitatively suggests the potential of MM5 as a source for correcting the WV effects at high resolution. Actually, considering the limitations of satellite NIR-based IWV estimates (i.e. day-time only, cloud blocking, sun glint, ocean screening), MERIS and MM5 seem complementary because MERIS provides actual IWV measurements at fine resolution with some gaps, while MM5 provides spatially and temporally continuous IWV forecasts.

The IWV maps produced by MM5 within the HR area have been validated against the IWV point-like observations by the GPS receivers. Figure 6 shows that MM5 agrees with GPS within $0.2 \mathrm{~cm} \mathrm{rms}$, confirming the results in Fig. $4 \mathrm{ob}-$ tained validating MM5 with the MWR at DIESAP. Similarly, 
MODIS and MERIS IWV estimates at their original horizontal resolution are compared against reference GPS IWV point-like sources. It is clear that MERIS NIR demonstrates much better agreement than both MODIS IR and NIR products with respect to GPS. The rms difference of MERIS IWV with respect to the reference GPS sources is better than $0.1 \mathrm{~cm}$, with a negligible bias $(<0.03 \mathrm{~cm})$, and correlation better than 0.97 . These results suggest that, once cloudand ocean-contaminated pixels have been properly screened, MERIS IWV can be adopted as a reference for high resolution IWV maps with an associated error within $0.1 \mathrm{~cm}$. This result is confirmed by the validation of MERIS IWV against MWR at DIESAP (rms difference $<0.1 \mathrm{~cm}$, not shown). Note that the Terra MODIS IWV from NIR shows a positive bias with respect to GPS $(0.2 \mathrm{~cm})$, which fits in the range reported by Serpolla et al. (2009), that is $0.2-0.7 \mathrm{~cm}$ depending upon location.

Thus, we hereafter assume MERIS IWV maps as the reference to compare against the IWV maps from other sources, such as MM5 forecast. The statistical comparison of MM5 IWV with respect to MERIS observations was performed on six cases during the WVIOP. For these six cases, the number of overlapping pixels range from 1730 to 7515 , with correlation coefficient ranging from 0.83 to 0.94 and rms difference ranging from 0.09 to $0.28 \mathrm{~cm}$. Taking all the cases as a whole (Fig. 7), the correlation coefficient is 0.94 and the rms difference is $0.18 \mathrm{~cm}$ (for a total of 43179 overlapping pixels). Our results are in line with those shown by Puyssègur et al. (2007), though the latter were obtained by manually discarding MERIS pixels that were judged to be likely contaminated by clouds remained undetected by the automatic screening.

Concerning the contribution of WV stratification, it is desirable to check the ability to reproduce the relationship between IWV and surface height. Thus, we derived this relationship from MM5 IWV maps and compared with the analogous derived from MERIS data for all the match-up cases during the WVIOP. The surface altitude was extracted from the DEM at 1-km resolution used within MM5. The results of this analysis are reported in Fig. 8, where we show scatter plots of linear-fit slope $(S)$ and offset $(O)$ parameters of the IWV vs. height trend computed for all the MERIS and MM5 match-up cases during the WVIOP. Figure 8 demonstrates that MERIS and MM5 are actually seeing similar trends at specific times, though the range of variation seems slightly larger for MM5 than for MERIS. From the 7 matchup cases it results that the $S$ and $O$ parameters agree within $0.11 \mathrm{~cm} \mathrm{~km}^{-1}$ and $0.19 \mathrm{~cm} \mathrm{rms}$, respectively. Finally, Table 3 summarizes that, using all the match-up cases as a whole, MM5 and MERIS provide IWV vs. altitude trends that are fairly comparable in a statistical sense: on a vertical scale of $1 \mathrm{~km}$ the IWV may vary from 0.55 to $1.07 \mathrm{~cm}$ according to MM5 and from 0.57 to $0.97 \mathrm{~cm}$ according to MERIS. In terms of estimated displacement, these figures roughly translate into values from about 3.7 to $6.5 \mathrm{~cm}$.
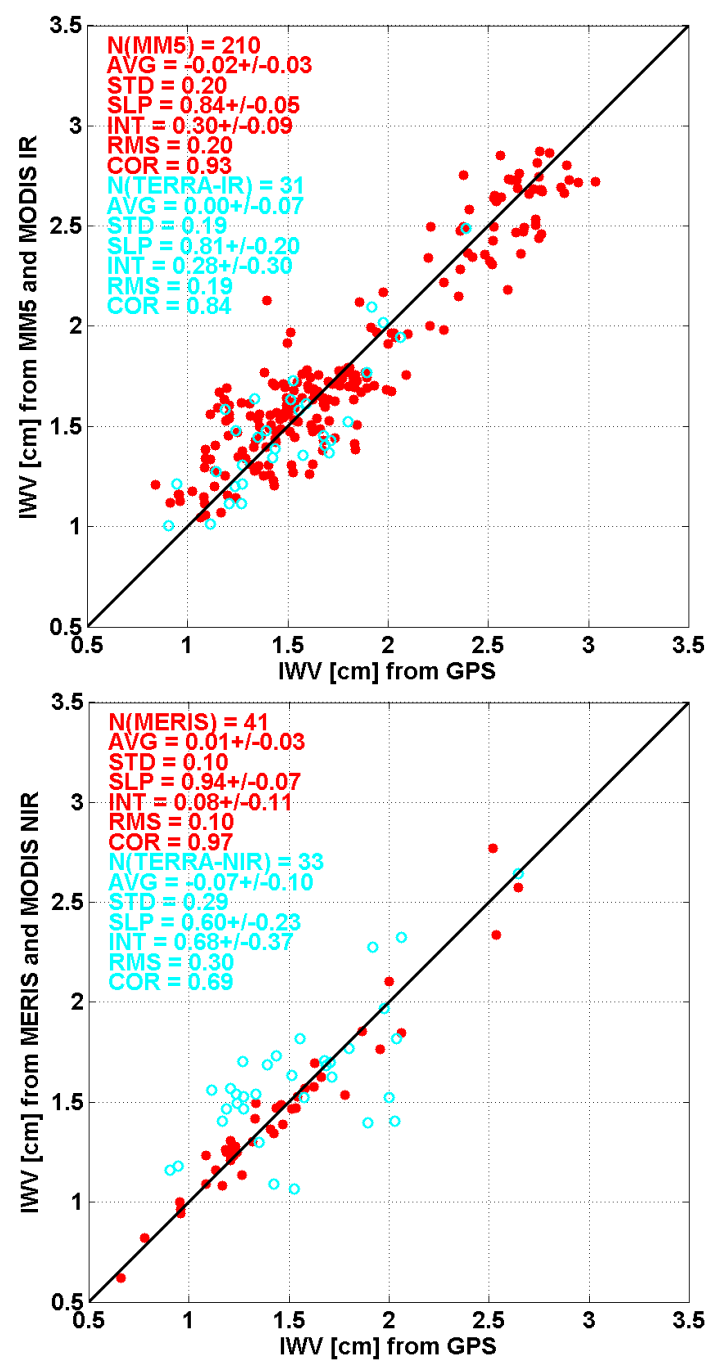

Fig. 6. Statistical comparison of IWV products from MM5 and MODIS IR (top) and MERIS and MODIS NIR (bottom) at their original horizontal resolution, against reference IWV from GPS network (as in Fig. 1).

In addition to the slope and offset of IWV with respect to altitude, it also important for the estimation of the vertical stratification to verify the ability to predict accurately the IWV anomaly (dIWV) with respect to altitude $(h)$, that is the difference between the actual IWV and the average IWV estimated as a function of altitude only (indicated as $\mathrm{IWV}_{\mathrm{m}}(h)=S_{\mathrm{m}} h+O_{\mathrm{m}}$ where $S_{\mathrm{m}}$ and $O_{\mathrm{m}}$ are the mean slope and offset, respectively):

$\mathrm{dIWV}_{\mathrm{m}}=\mathrm{IWV}-\operatorname{IWV}_{\mathrm{m}}(h)$

In addition to $\operatorname{IWV}_{\mathrm{m}}(h)$ we also consider $\operatorname{IWV}_{i}(h)$, that is the IWV estimated as a function of altitude for each different match-up case $\left(\operatorname{IWV}_{i}(h)=S_{i} h+O_{i}\right.$ where $S_{i}$ and $O_{i}$ are the slope and offset estimated for the $i$ th match-up case). In this 


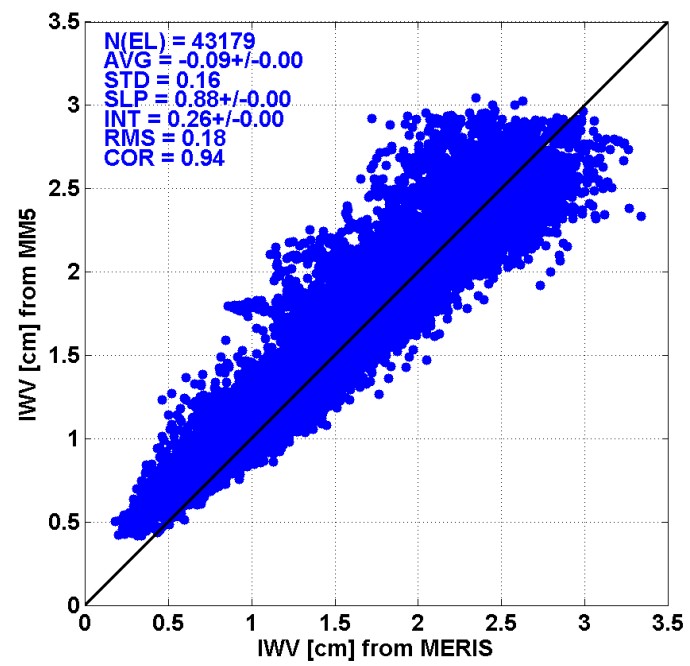

Fig. 7. Statistics of MM5 vs. MERIS IWV maps for all the matchup cases during the WVIOP.

Table 3. Slope $(S)$ and offset $(O)$ of the IWV vs. height linear fit as extracted from the MERIS-MM5 IWV match-ups cases. The numbers after \pm indicate $95 \%$ confidence interval.

\begin{tabular}{lrr}
\hline & $S\left(\mathrm{~cm} \mathrm{~km}^{-1}\right)$ & $O(\mathrm{~cm})$ \\
\hline MM5 & $-0.81 \pm 0.26$ & $1.98 \pm 0.48$ \\
MRS & $-0.77 \pm 0.20$ & $1.86 \pm 0.47$ \\
\hline
\end{tabular}

case, the anomaly is

$\mathrm{dIWV}_{i}=\mathrm{IWV}-\operatorname{IWV}_{i}(h)$

In other words, we compute the anomaly with respect to an average stratification for a long period of time $\left(\operatorname{IWV}_{\mathrm{m}}(h)\right)$ and an "instantaneous" spatially averaged stratification $\left(\operatorname{IWV}_{i}(h)\right)$. Figure 9 shows what happens when we apply Eqs. (4) or (5) to the whole match-up data set. Using Eq. (4) the values of $\mathrm{dIWV}_{\mathrm{m}}$ estimated from MERIS and MM5 show $\sim 0.16 \mathrm{~cm}$ rms differences with negligible bias $(\sim 0.01 \mathrm{~cm})$ and good correlation coefficient $(\sim 0.92)$. Using Eq. (5), the rms difference remains nearly the same $(0.15 \mathrm{~cm})$ but the correlation coefficient drops to $\sim 0.43$. This is due to the residual stratification term (correlated with height) that is present in $\mathrm{dIWV}_{\mathrm{m}}$ (being the anomaly with respect to the average $\operatorname{IWV}_{\mathrm{m}}(h)$ ) but that is largely removed from $\operatorname{dIWV}_{i}$ (being the anomaly with respect to $\operatorname{IWV}_{i}(h)$ estimated from each single match-up case). The rms on $\mathrm{dIWV}_{i}$ thus represents an estimate of the rms difference on the residual turbulent term. Analyzing $\mathrm{dIWV}_{i}$ for each single case independently, we found that the correlation coefficient ranges from 0.6 to 0.7 in most of the cases, though there are two cases in which the correlation is $\sim 0.4$ and one in which is very poor $(\sim 0.2)$.

Therefore, from the analysis of IWV with respect to altitude, we can conclude that MM5 and MERIS show con-
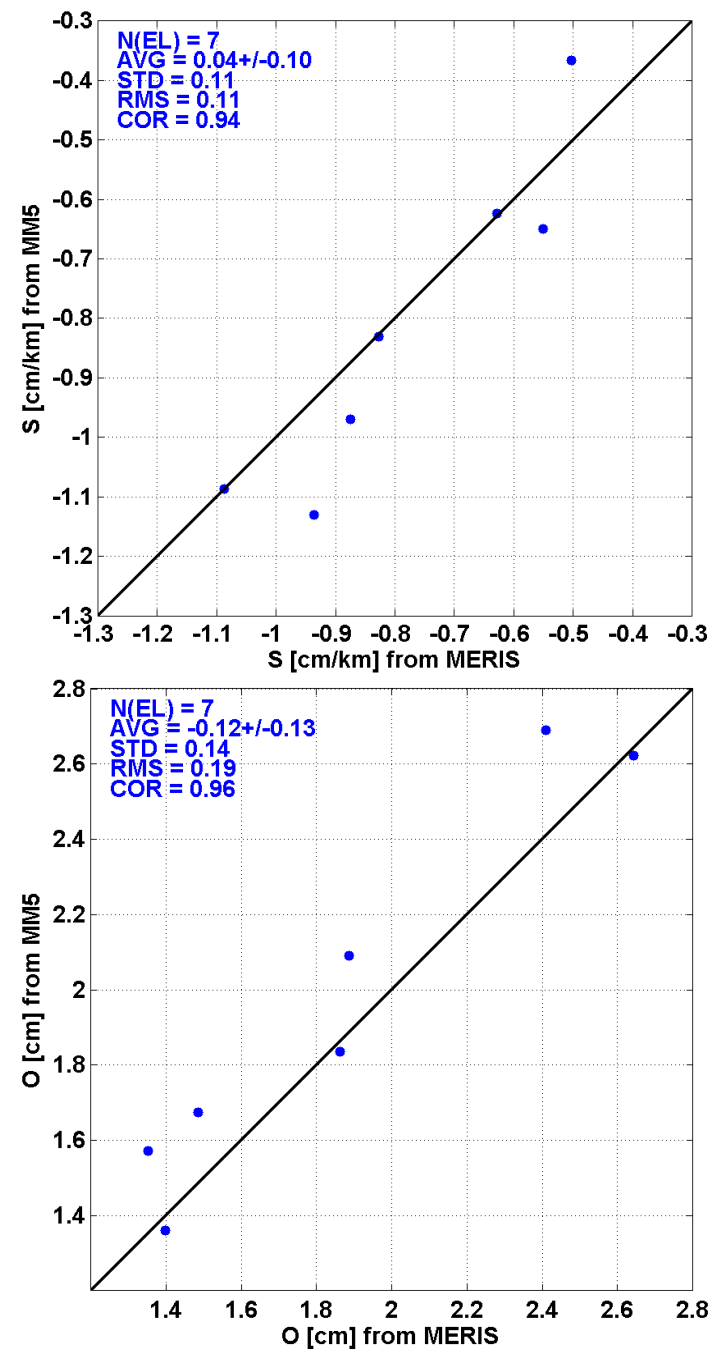

Fig. 8. Scatter plots of slopes $S$ (top) and offsets $O$ (bottom) of IWV vs. height trends extracted from MM5 and MERIS data from the 7 match-up cases during the WVIOP.

sistent trends for what concerns IWV absolute values. For the anomalies dIWV the trend seems consistent for most of, but not all, the cases, though the correlation of the turbulent terms is modest (from 0.2 to 0.7 ). A future study shall investigate on possible connections between the meteorological conditions and the consistency of dIWV vs. $h$ trends. Moreover, given the high resolution of MERIS IWV and the accuracy demonstrated here, future work shall be dedicated to the improvement of MM5 IWV field by 3-D variational (3-DVAR) data assimilation of MERIS IWV.

\subsection{IWV triple collocation}

In this section, the results for the so-called triple collocation analysis described by Stoeffelen (1998) are presented. The three sources of IWV data considered here are the groundbased GPS receiver network, the satellite based MERIS 

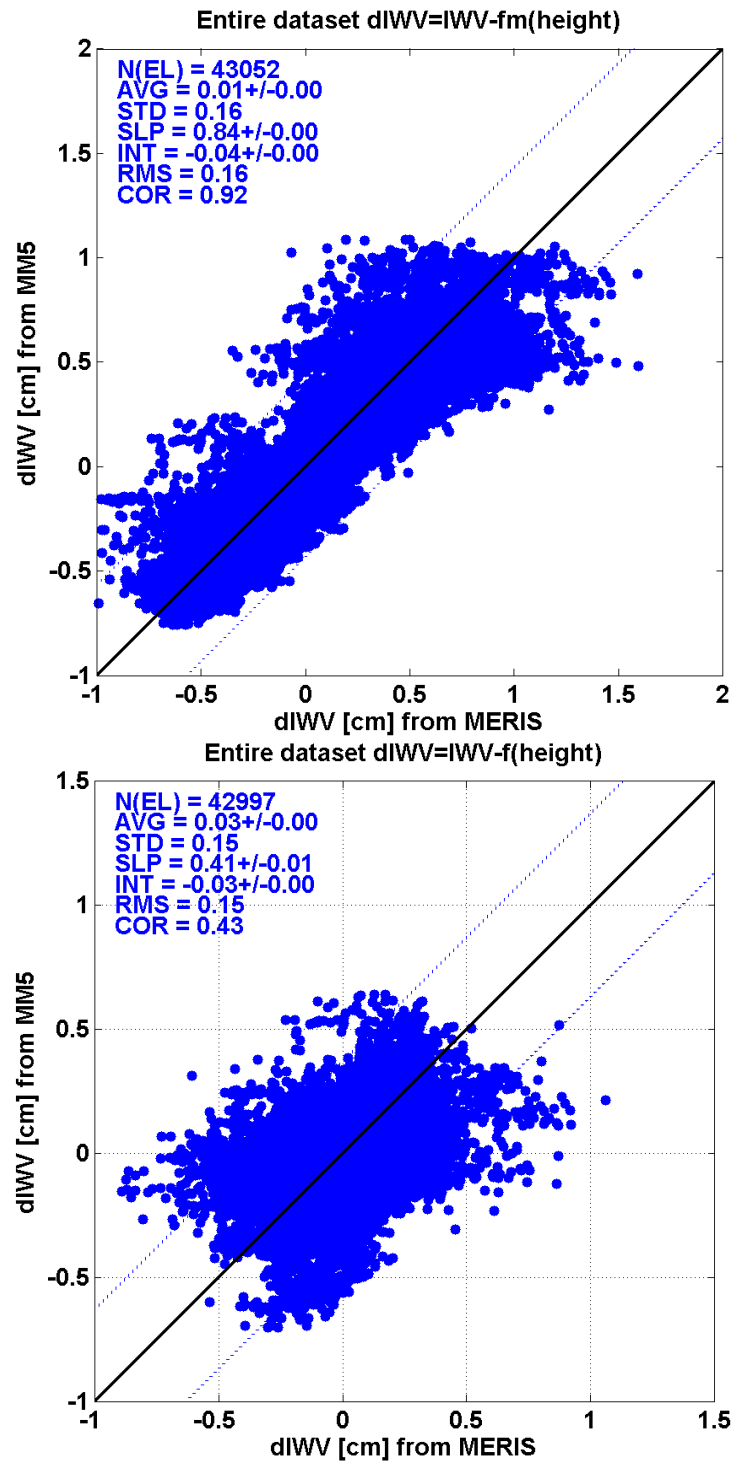

Fig. 9. Scatter plots of MM5 vs. MERIS IWV residuals for all the match-up cases during the WVIOP. Residuals have been computed using the two methods described in the text. Top: $\mathrm{dIWV}_{\mathrm{m}}=\mathrm{IWV}$ $\operatorname{IWV}_{\mathrm{m}}(h)$. Bottom: dIWV $i=\operatorname{IWV}_{i} \operatorname{IWV}_{i}(h)$.

retrievals, and the MM5 NWP model output. Since the true variable is always unknown, one of the datasets needs to be chosen as a reference. This means that errors will be expressed in the observation space of the selected reference, though the choice of the reference dataset does not influence the relative magnitude of the errors, which can be scaled from one observation space into the other. Here we arbitrarily chose the GPS as the reference and determine the scaling constants of the other two sources with respect to that. GPS, MERIS, and MM5 are hereafter referred as system X, $\mathrm{Y}$, and Z, respectively. As briefly described in Sect. 3, validation parameters for systems $\mathrm{Y}$ and $\mathrm{Z}$ with respect to $\mathrm{X}$ and random errors of all observation systems $\mathrm{X}, \mathrm{Y}$, and $\mathrm{Z}$
Table 4. Validation parameters and random errors estimated for GPS ( $x$ ), MERIS ( $y$ ), and MM5 ( $z$ ) IWV estimates using triple collocation analysis for six assumed values of the correlated part of the representativeness error $r^{2}$.

\begin{tabular}{rrrrrrr}
\hline $\begin{array}{r}r^{2} \\
\left(\mathrm{~cm}^{2}\right)\end{array}$ & $s_{y}$ & $s_{z}$ & $\begin{array}{r}\varepsilon_{x} \\
(\mathrm{~cm})\end{array}$ & $\begin{array}{r}\varepsilon_{y} \\
(\mathrm{~cm})\end{array}$ & $\begin{array}{r}\varepsilon_{z} \\
(\mathrm{~cm})\end{array}$ & $\begin{array}{r}\sigma \\
(\mathrm{cm})\end{array}$ \\
\hline 0.000 & 0.990 & 0.860 & 0.094 & 0.054 & 0.169 & 0.439 \\
0.001 & 0.990 & 0.865 & 0.099 & 0.062 & 0.165 & 0.438 \\
0.002 & 0.990 & 0.869 & 0.104 & 0.070 & 0.161 & 0.436 \\
0.003 & 0.990 & 0.874 & 0.109 & 0.077 & 0.157 & 0.435 \\
0.004 & 0.990 & 0.879 & 0.113 & 0.083 & 0.153 & 0.434 \\
0.005 & 0.990 & 0.883 & 0.118 & 0.089 & 0.149 & 0.433 \\
\hline
\end{tabular}

can be easily determined if an estimate of $r^{2}$, the correlated part of the representativeness errors of $\mathrm{X}$ and $\mathrm{Y}$, is available. Here we follow the modification of the input data used in Caires and Sterl (2003): instead of using the original absolute IWV values, we base our analysis on IWV anomalies with respect to the mean. As discussed in Dorigo et al. (2010), the anomaly-based approach does not reveal about absolute deviations between datasets, e.g. bias introduced by instruments or model, but on the ability of the different datasets to capture variations.

Theoretically, an infinite number of collocated triplets are required to obtain unbiased estimates of the errors. Though Scipal et al. (2008) suggest 100 as a good trade-off number of triplets, the following results were obtained from the set of independent triple collocations that could be extracted from the WVIOP dataset (30).

The validation parameters and random errors from the above procedure are shown in Table 4 for different values of $r^{2}$. A study of IWV spatial representation at different scales is found in Montopoli et al. (2011), where we find that on larger scales MM5 contains significantly less variance than GPS and MERIS. It is likely that part of the additional variance in GPS and MERIS verifies with the true IWV and that the rest is caused by the instrumental error. Building on these results, we estimate that reasonable values for $r^{2}$ are of the order of $\sim 0 . \mathrm{cm}^{2}$. However, in Table 4 we report results for few $r^{2}$ values ranging from 0 to $0.005 \mathrm{~cm}^{2}$, demonstrating that the sensitivity of the results to the choice of $r^{2}$ is small. Note that this holds also for $r^{2}=0$, i.e. assuming MERIS and GPS have no correlated representativeness error. This latter case is formally identical to the functional relationship model formalism suggested in Caires and Sterl (2003), and indeed the quantitative results are consistent with those of that model. From Table 4 we conclude that at the scale of $\sim 1 \mathrm{~km}$ :

- the variance of the true IWV field is $\sim 0.43-0.44 \mathrm{~cm}$

- the GPS, MERIS, and MM5 random errors are $\sim 0.09-0.11 \mathrm{~cm}, \quad \sim 0.05-0.09 \mathrm{~cm}$, and $0.15-0.17 \mathrm{~cm}$, respectively 
- the MERIS observations appear scaled high by less than $1 \%$ with respect to GPS

- the MM5 forecasts appear to be scaled high by some $12-14 \%$ with respect to GPS.

As one would expect, the results do not differ significantly if we consider MERIS as the reference instead of GPS (not shown).

\subsection{Summary}

The results discussed above are summarized in the following, with special emphasis to IWV since it is the focus of the METAWAVE project and WVIOP:

- IWV estimates from RAOB, MWR, and GPS have been mutually validated, resulting in rms differences within $0.1 \mathrm{~cm}$, with small biases $(\sim 0.02-0.04 \mathrm{~cm})$ and excellent correlation $(>0.97)$.

- IWV from MM5 has been validated against RAOB, MWR, and GPS, resulting in rms differences within $0.2 \mathrm{~cm}$, with small biases $(\sim 0.02-0.09 \mathrm{~cm})$ and correlation better than 0.90 .

- IWV from MODIS NIR has been validated against MWR and GPS, resulting in rms differences within $0.2-0.3 \mathrm{~cm}$, with significant biases $(\sim 0.1-0.2 \mathrm{~cm})$ and correlation ranging from 0.37 to 0.92 .

- IWV from MERIS NIR has been validated against MWR and GPS, resulting in rms differences within $0.1 \mathrm{~cm}$, with small biases $(\sim 0.03 \mathrm{~cm})$ and excellent correlation $(>0.97)$.

Moreover, the analysis produced the following results:

- IWV maps from MM5 have been validated against MERIS maps, resulting in rms differences from 0.09 to $0.28 \mathrm{~cm}$, with small-to-moderate biases $(\sim 0.01-$ $0.15 \mathrm{~cm}$ ) and correlation ranging from 0.83 to 0.94 , depending upon case. Considering all the cases as a whole, MM5 agrees with MERIS within $0.18 \mathrm{~cm}$ rms difference with $\sim 0.1 \mathrm{~cm}$ wet bias and 0.94 correlation.

- IWV maps from MM5 show a trend with height that is consistent with what observed by MERIS; the mean linear-fit slopes differ by $\sim 5 \%$. Considering the trend of IWV anomaly (i.e. dIWV), results from MM5 are usually well correlated with those from MERIS (correlation coefficients ranging from 0.43 to 0.77 ).

Finally, performing a triple collocation analysis among GPS, MERIS, and MM5 at the scale of $\sim 1 \mathrm{~km}$ we showed that:

- the variance of the true IWV field is $\sim 0.43-0.44 \mathrm{~cm}$

- the GPS, MERIS, and MM5 random errors are within $\sim 0.09-0.11 \mathrm{~cm}, \sim 0.05-0.09 \mathrm{~cm}$, and $0.15-0.17 \mathrm{~cm}$, respectively
- the MERIS observations appear biased high by less than $1 \%$ with respect to GPS

- the MM5 forecasts appear to be biased high by some $12-14 \%$ with respect to GPS.

The number above summarize the accuracy in estimating the IWV from radiosondes and ground-based MWR and GPS, which however can provide only point-like measurements. In addition, it is shown that the best accuracy and spatial resolution is achieved with MERIS, with the main drawback deriving from the unavailability of IWV estimates in cloudy conditions and during night time. Since MERIS and ASAR both fly onboard ENVISAT, and thus can take spatially and temporally co-registered observations, MERIS may be in principle particularly useful for InSAR WV effect mitigation. However, the end of the ENVISAT life-time is approaching and to our knowledge there is no plan to have a comparable sensor combination in the future.

The ultimate question is whether these accuracies are enough to provide a reliable means for InSAR to mitigate the electromagnetic delay generated by WV. To answer this question three main points have to be recalled. (a) InSAR is a differential measurement, carried out between pairs of images acquired at different times. As a consequence, IWV maps affect InSAR imaging as differences between atmospheric conditions at different times. The signal of interest in InSAR is thus constrained to variations instead of absolute values. (b) By means of multi-temporal analysis, like the PS technique (Ferretti et al., 2001), InSAR is able to achieve point-wise measurements with a spatial density of up to thousands points per $\mathrm{km}^{2}$ nowadays (Gernhardt et al., 2010). (c) Given the phase stability of PSs, by interpolating the WV delay estimate, even in areas presenting few PS, within $1 \mathrm{~km}$ the achievable precision is of the order of $\sim 0.1 \mathrm{~cm}$ in path delay (Perissin et al., 2011), i.e. $\sim 0.017 \mathrm{~cm}$ in IWV. Thus, it would require an observing/modelling system with an accuracy better than $\sim 0.017 \mathrm{~cm}$ operating simultaneously with a SAR instrument for filtering out atmospheric signal in clear-sky conditions point by point. From the analysis above, we conclude that InSAR has much higher sensitivity to WV turbulent component (fractions of mm IWV in few hundreds meters) than the instruments analyzed here. Nonetheless, IWV observations by MERIS and by MWR and/or GPS networks, as well as IWV simulations by MM5 and/or ECMWF, can provide valuable aid to estimate the IWV vertical stratification, to suppress the long spatial wavelength $(>20 \mathrm{~km})$ component of the atmospheric delay, and thus significantly improve the performances of InSAR phase unwrapping techniques.

\section{Conclusions}

We have performed a comparison of water vapor observations and numerical model predictions collected during a 
2-week experimental campaign carried out in the frame of the ESA METAWAVE project. Although the METAWAVE project focused on water vapor effects on SAR interferograms, a more general assessment of the water vapor accuracy obtained by different observational techniques and numerical methods was achieved. Radiosoundings, ground based microwave radiometer and GPS receivers, spaceborne infrared radiometers, ECMWF analysis and MM5 forecast were compared in terms of their ability to provide accurate water vapor estimates. A triple-collocation analysis was performed to account for the inherent noise in each observing/modelling system. In conclusion, we have assessed the good performances of ground based radiometers and GPS receivers point-wise observations (IWV rms errors $\sim 0.07 \mathrm{~cm}$ and correlations greater than 0.97). The MERIS infrared radiometer aboard of ENVISAT proved to be the most accurate tool to map IWV at high resolution (rms error $\sim 0.08 \mathrm{~cm}$ ), whereas MODIS showed significantly lower performances (rms error $\sim 0.18 \mathrm{~cm}$ ). Numerical predictions from the $1-\mathrm{km}$ resolution mesoscale model MM5 showed IWV accuracy similar to MODIS $(\sim 0.16 \mathrm{~cm})$. From numerical modelling point of view this level of accuracy can be considered satisfactory with the advantage of temporal and spatial continuity of the IWV field. The differences with respect to MERIS may be due to the model lower resolution, uncertainties in soil moisture, and subgrid turbulence mechanisms that are not well represented at scales higher than $1 \mathrm{~km}$.

Finally, for what concerns the main focus of the METAWAVE project, that is the ability to mitigate the water vapor effect on the InSAR electromagnetic path delay and thus on the interferogram phase, considering the level of accuracy achieved by multi-temporal analysis $(\sim 0.017 \mathrm{~cm}$ in IWV), the above findings indicate that the IWV sources analyzed here have not enough sensitivity to the turbulent component to correct InSAR electromagnetic path delay point by point. Nonetheless, information on the IWV vertical stratification from observations (as MERIS and/or GPS network) and simulations (as MM5/ECMWF) can provide valuable aid to suppress the long spatial wavelength $(>20 \mathrm{~km}$ ) component of the atmospheric delay, contributing to the improvement of the performances of InSAR phase unwrapping techniques.

Acknowledgements. The authors are grateful to the National Center for Aeronautic Meteorology and Climatology (CNMCA) of USAM for the RAOB launched at PDM and to the Colorado State University for providing the portable radiosonde station used to gather RAOB data at DIESAP. Patrizia Basili and Piero Ciotti are kindly acknowledged for computing the GPS zenith total delay. The lead author is grateful to Barry Vanhoff for the details on triple-collocation implementation. Finally, the authors acknowledge the support of ESA through the METAWAVE project ESA/ESTEC contract No. 21207/07/NL/HE.

Edited by: S. Buehler

\section{References}

Basili, P., Bonafoni, S., Mattioli, V., Ciotti, P., and Pierdicca, N.: Mapping the atmospheric water vapor by integrating microwave radiometer and GPS measurements, IEEE T. Geosci. Remote, 42, 1657-1665, 2004.

Bevis, M., Businger, S., Herring, T. A., Rocken, C., Anthes, R. A., and Ware, R. H.: GPS Meteorology' Remote Sensing of Atmospheric Water Vapor Using the Global Positioning System, J. Geophys. Res., 97, 15787-15801, 1992.

Bevis, M., Businger, S., Chiswell, S., Herring, T. A., Anthes, R. A., Rocken, C., and Ware, R. H.: GPS meteorology: mapping zenith wet delays onto precipitable water, J. Appl. Meteorol., 33, 379386, 1994.

Bock, O., Keil, C., Richard, E., Flamant, C., and Bouin, M.-N.: Validation of precipitable water from ECMWF model analyses with GPS and radiosonde data during the MAP SOP, Q. J. Roy. Meteorol. Soc., 131, 3013-3036, 2006.

Bonforte, A., Ferretti, A., Prati, C., Puglisi, G., and Rocca, F.: Calibration of atmospheric effects on SAR interferograms by GPS and local atmosphere models: First results, J. Atmos. Sol. Terr. Phys., 63, 1343-1357, 2001.

Caires, S. and Sterl, A.: Validation of ocean wind and wave data using triple collocation, J. Geophys. Res., 108, 3098, doi:10.1029/2002JC001491, 2003.

Cimini, D., Westwater, E. R., Han, Y., and Keihm, S. J.: Accuracy of Ground-based Microwave Radiometer and BalloonBorne Measurements During WVIOP2000 Field Experiment, IEEE T. Geosci. Remote, 41, 2605-2615, 2003.

Davis, J. L., Herring, L. T. A., Shapiro, I. I., Rogers, A. E., and Elgered, G.: Geodesy by radio interferometry: Effects of atmospheric modelling errors on estimates of baseline length, Radio Sci., 20, 1593-1607, 1985.

Desportes, C., Obligis, E., and Eymard, L.: On the Wet Tropospheric Correction for Altimetry in Coastal Regions, IEEE T. Geosci. Remote, 45, 2139-2149, 2007.

Doin, M. P., Lasserre, C., Peltzer, G., Cavalie, O., and Doubre, C.: Corrections of stratified tropospheric delays in SAR interferometry: Validation with global atmospheric models, J. Appl. Geophys., 69, 35-50, 2009.

Dorigo, W. A., Scipal, K., Parinussa, R. M., Liu, Y. Y., Wagner, W., de Jeu, R. A. M., and Naeimi, V.: Error characterisation of global active and passive microwave soil moisture datasets, Hydrol. Earth Syst. Sci., 14, 2605-2616, doi:10.5194/hess-14-26052010, 2010.

Dudhia, J.: A nonhydrostatic version of the Penn State-NCAR Mesoscale Model: Validation tests and simulation of an Atlantic cyclone and cold front, Mon. Weather Rev., 121, 1493-1513, 1993.

Elgered, G.: Tropospheric radio-path delay from ground-based microwave radiometry, in: Atmospheric Remote Sensing by Microwave Radiometry, edited by: Janssen, M. A., New York, J. Wiley \& Sons, Inc, 1993, Chap. 4, 215-258, 1993.

Ferretti, A., Prati, C., and Rocca, F.: Permanent Scatterers in SAR interferometry, IEEE T. Geosci. Remote, 39, 8-20, January, 2001.

Ferretti, R., Mastrantonio, G., Argentini, S., Santoleri, L., and Viola, A.: A model-aided investigation of winter thermally driven circulation in the Italian Tyrrhenian coast for a case study, J. Geophys. Res., 108, 4777-4792, 2003. 
Fischer, J. and Bennartz, R.: Retrieval of total water vapour content from MERIS meansurements, ESA reference number PO-TNMEL-GS-005, ESA-ESTEC, Noordwijk, The Netherlands, 1997.

Freilich, M. H. and Vanhoff, B. A.: QuikSTAT vector wind accuracy: Initial esimates. Proc. QuikSTAT Cal/Val Early Science Meeting, Pasadena, CA, Jet Propulsion Laboratory, 1999.

Freilich, M. H. and Vanhoff, B. A.: The accuracy of remotely sensed surface wind speed measurements, unpublished data, 2001.

Gao, B. C. and Kaufman, Y.: Water vapour retrievals using Moderate Resolution Imaging Spectroradiometer (MODIS) near-infrared channels, J. Geophys. Res., 108, 4389, doi:10.1029/2002JD003023, 2003.

Gens, R. and Van Genderen, J. L.: Review Article SAR interferometry - issues, techniques, applications, Int. J. Remote Sens., 17, 1803-1835, doi:10.1080/01431169608948741, 1996.

Gernhardt, S., Adam, N., Eineder, M., and Bamler, R.: Potential of Very High Resolution SAR for Persistent Scatterer Interferometry in Urban Areas, Annals of GIS, 16, 103-111, 2010.

Gutman, S. I., Sahm, S. R., Benjamin, S. G., and Smith, T. L.: GPS water vapor observation errors., 8th Symposium on Integrated Observing and Assimilation Systems for Atmosphere, Oceans, and Land Surface, paper 8.3, Seattle, WA, Am. Meteorol. Soc., , 2004.

Hanssen, R. F., Weckwerth, T. M., Zebker, H. A., and Klees, R.: High-resolution water vapour mapping from interferometric radar measurements, Science, 283, 5406, doi:10.1126/science.283.5406.1297, 1999.

Hanssen, R. F.: Radar Interferometry: Data Interpretation and Error Analysis, 308 pp., Springer, New York, 2001.

King, M. D., Menzel, W. P., Kaufman, Y. J., Tanre, D., Gao, BoCai, Platnick, S., Ackerman, S. A., Remer, L. A., Pincus, R., and Hubanks, P. A.: Cloud and aerosol properties, precipitable water, and profiles of temperature and humidity from MODIS. IEEE T. Geosci. Remote, 41, 442-458, doi:10.1109/TGRS.2002.808226, 2003.

Li, Z., Muller, J. P., Cross, P., Albert, P., Fischer, J., and Bennartz, R.: Assessment of the potential of MERIS near-infrared water vapour products to correct ASAR interferometric measurements, Int. J. Remote Sens., 27 349-365, 2006

Massonnet, D. and Feigl, K. L.: Radar interferometry and its application to changes in the earth's surface, Rev. Geophys., 36, 441-500, doi:10.1029/97RG03139, 1998

Mattioli, V., Westwater, E. R., Gutman, S., and Morris, V.: Forward Model Studies of Water Vapour using Scanning Microwave Radiometers, Global Positioning System and Radiosondes during the Cloudiness Inter-Comparison Experiment, IEEE T. Geosci. Remote, 43, 1012-1021, 2005.

Mattioli, V., Westwater, E. R., Cimini, D., Liljegren, J. S., Lesht, B. M., Gutman, S. I., and Schmidlin, F. J.: Analysis of Radiosonde and Ground-based Remotely Sensed PWV data from the 2004 North Slope of Alaska Arctic Winter Radiometric Experiment, J. Atmos. Ocean. Technol., 24, 415-431, 2007.

Michalakes, J., Dudhia, J., Gill, D., Klemp, J., and Skamarock, W.: Design of a next-generation regional weather research and forecast model: Towards Teracomputing, World Scientific, River Edge, New Jersey, 117-124, 1998.

Miralles, D. G., Crow, W. T., and Cosh, M. H.: Estimating spatial sampling errors in coarsescale soil moisture estimates derived from pointscale observations, J. Hydrometeorol., 11, 1423-1429,
doi:10.1175/2010JHM1285.1, 2010.

Montopoli, M., Pierdicca, N., and Marzano, F. S.: Spectral downscaling of integrated water vapor fields from satellite infrared observations, IEEE T. Geosci. Remote, 99, 1-14, doi:10.1109/TGRS.2011.2161996, 2011

Niell, A. E., Coster, A. J., Solheim, F. S., Mendes, V. B., Toor, P. C., Langley, R. B., and Upham, C. A.: Comparison of Measurements of Atmospheric Wet Delay by Radiosonde, Water Vapor Radiometer, GPS, and VLBI, J. Atmos. Ocean. Technol., 18, 830-850, 2001.

Onn, F. and Zebker, H.: Correction for interferometric synthetic aperture radar atmospheric phase artefacts using time series of zenith wet delay observations from a GPS network, J. Geophys. Res., 111, B09102, doi:10.1029/2005JB004012, 2006.

Perissin, D. and Rocca, F.: High accuracy urban DEM using Permanent Scatterers, IEEE T. Geosci. Remote, 44, 3338-3347, 2006.

Perissin, D. and Ferretti, A.: Urban target recognition by means of repeated spaceborne SAR images, IEEE T. Geosci. Remote, 45, 4043-4058, 2007.

Perissin, D., Rocca, F., Pierdicca, M., Pichelli, E., Cimini, D., Venuti, G., Rommen, and B.: Mitigation of Atmospheric Delay In InSAR: The ESA METAWAVE Project, Proc. of IGARSS, 2429 July 2011, 2558-2561, doi:10.1109/IGARSS.2011.6049734, 2011.

Puysségur, B., Michel, R., and Avouac, J.-P.: Tropospheric phase delay in interferometric synthetic aperture radar estimated from meteorological model and multispectral imagery, J. Geophys. Res., 112, B05419, doi:10.1029/2006JB004352, 2007.

Quilfen, Y., Chaprond, B., and Vandemark, D.: The ERS Scatterometer Wind Measurement Accuracy: Evidence of Seasonal and Regional Biases, J. Atmos. Ocean. Technol., 18, 1684-1697, 2001.

Revercomb, H. E., Turner, D. D., Tobin, D. C., Knuteson, R. O., Feltz, W. F., Barnard, J., Bösenberg, J., Clough, S., Cook, D., Ferrare, R., Goldsmith, J., Gutman, S., Halthore, R., Lesht, B., Liljegren, J., Linné, H., Michalsky, J., Morris, V., Porch, W., Richardson, S., Schmid, B., Splitt, M., Van Hove, T., Westwater, E., and Whiteman, D.: The ARM program's water vapor intensive observation periods: Overview, initial accomplishments, and future challenges, B. Am. Meteor. Soc., 84, 217-236, 2003.

Saastamoinen, J.: Atmospheric Correction for the Troposphere and Stratosphere in Radio Ranging of Satellites, The Use of Artificial Satellites for Geodesy, 15, edited by: Henriksen, S. W., Mancini, A., and Chovitz, B. H., Geophysics Monograph Series, A.G.U., Washington, D.C., 1972.

Sahoo, S., Reising, S. C., Padmanabhan, S., Vivekanandan, J., Iturbide-Sanchez, F., Pierdicca, N., Pichelli, E., and Cimini, D.: 3-D Humidity Retrieval Using a Network of Compact Microwave Radiometers to Correct For Variations In Wet Tropospheric Path Delay In Spaceborne Interferometric SAR Imagery, IEEE T. Geosci. Remote, 49, 3281-3290, doi:10.1109/TGRS.2011.2119400, 2011.

Scipal, K., Holmes, T. R., de Jeu, R., Naeimi, V., and Wagner, W.: A possible solution for the problem of estimating the error structure of global soil moisture data sets, Geophys. Res. Lett., 35, L24403, doi:10.1029/2008GL035599, 2008.

Serpolla, A., Bonafoni, S., Biondi, R., Arinò, O., and Basili, P.: Validation of near infrared satellite based algorithms to retrieve atmospheric water vapour content over land, Italian Journal of Remote Sensing, 41, 37-44, 2009. 
Solheim, F. S., Vivekanandan, J., Ware, R. H., and Rocken, C.: Propagation delays induced in GPS signals by dry air, water vapor, hydrometeors, and other particulates, J. Geophys. Res., 104, 9663-9670, 1999.

Stoffelen, A.: Toward the true near-surface wind speed: Error modeling and calibration using triple collocation, J. Geophys. Res., 103, 7755-7766, 1998.

Treuhaft, R. N. and Lanyi, G. E.: The effect of dynamic wet troposphere on radio interferometric measurements, Radio Sci., 22, 251-265, 1987.
Vömel, H., Selkirk, H., Miloshevich, L., Valverde, J., Valdés, J., Kyrö, E., Kivi, R., Stolz, W., Peng, G., and Diaz, J. A.: Radiation dry bias of the Vaisala RS92 humidity sensor, J. Atmos. Ocean. Technol., 24, 953-963, 2007.

Zebker, H. A. and Goldstein, R. M.: Topographic mapping from interferometric synthetic aperture radar observations, J. Geophys. Res., 91, 4993-4999, 10 April, 1986.

Zebker, H. A., Rosen, P. A., and Hensley, S.: Atmospheric effects in interferometric synthetic aperture radar surface deformation and topographic maps, J. Geophys. Res., 102, 7547-7563, 1997. 